\title{
GCU
}

Glasgow Caledonian

University

University for the Common Good

\section{SDMF based interference rejection and PD interpretation for simulated defects in HV cable diagnostics}

Peng, Xiaosheng; Wen, Jinyu; Li, Zhaohui; Yang, Guangyao; Zhou, Chengke; Reid, Alistair; Hepburn, Donald M.; Judd, Martin D.; Siew, W.H.

Published in:

IEEE Transactions on Dielectrics and Electrical Insulation

DOI:

10.1109/TDEI.2016.006002

Publication date:

2017

Document Version

Author accepted manuscript

Link to publication in ResearchOnline

Citation for published version (Harvard):

Peng, X, Wen, J, Li, Z, Yang, G, Zhou, C, Reid, A, Hepburn, DM, Judd, MD \& Siew, WH 2017, 'SDMF based interference rejection and PD interpretation for simulated defects in HV cable diagnostics', IEEE Transactions on Dielectrics and Electrical Insulation, vol. 24, no. 1, pp. 83-91. https://doi.org/10.1109/TDEl.2016.006002

\section{General rights}

Copyright and moral rights for the publications made accessible in the public portal are retained by the authors and/or other copyright owners and it is a condition of accessing publications that users recognise and abide by the legal requirements associated with these rights.

Take down policy

If you believe that this document breaches copyright please view our takedown policy at https://edshare.gcu.ac.uk/id/eprint/5179 for details

of how to contact us. 


\title{
SDMF based Interference Rejection and PD Interpretation for Simulated Defects in HV Cable Diagnostics
}

\author{
Xiaosheng Peng, Jinyu Wen, Zhaohui Li, Guangyao Yang \\ State Key Laboratory of Advanced Electromagnetic Engineering and Technology \\ School of Electrical and Electronic Engineering \\ Huazhong University of Science and Technology, Wuhan, China, 430074
}

\author{
Chengke Zhou, Alistair Reid, Donald M. Hepburn \\ School of Engineering and Built Environment \\ Glasgow Caledonian University \\ Cowcaddens Road, Glasgow, UK, G4 0BA
}

\author{
Martin D. Judd and W. H. Siew \\ Department of Electronic \& Electrical Engineering \\ University of Strathclyde \\ Royal College, 204 George Street, Glasgow, UK, G1 1XW
}

\begin{abstract}
Partial Discharge (PD) in cable systems causes deterioration and failure, identifying the presence of PD is crucial to Asset Management. In this paper presents methods for interference signals rejection and for PD interpretation for five types of artificial defect in $11 \mathrm{kV}$ ethylene-propylene rubber (EPR) cable. Firstly, the physical parameters of the artificial defects used for PD signal generation are introduced. Thereafter, the sample stress regime, PD testing and detection systems, including IEC 60270 measurement system and High Frequency Current Transformer (HFCT), are outlined. Following on, a novel Synchronous Detection and Multi-information Fusion (SDMF) based signal identification method is developed, to separate PD and interference signals within raw data. Finally, a comparative PD analysis of two detection systems is carried out and several characteristics of insulation related PD signals of EPR cables are reported. The SDMF based data pre-processing and the comparative PD activity analysis contribute to improvement of PD pattern recognition and assist in on-line PD monitoring systems.
\end{abstract}

Index Terms - Partial Discharge, Cable System, Signal Identification, Interference Rejection, Feature Extraction.

\section{INTRODUCTION}

PARTIAL Discharge (PD) based condition monitoring systems have been increasingly adopted for power apparatus in recent years ${ }^{[1-4]}$. For successful $\mathrm{PD}$ recognition and interpretation in Medium Voltage (MV) and High Voltage (HV) cables there are two essential challenges which need to be overcome.

Firstly, most of the research into PD in cables is based on IEC60270 systems, e.g. ${ }^{[5-8]}$. The authors contend that the characteristics of PD signals from cables that are detected by commercial HFCT sensors need to be studied in more detail. For most on-line PD monitoring systems it is difficult to correlate PD signals with corresponding cable defect types as, if cable maintenance is not carried out after PD signals are detected, then the fault is damaged beyond recognition, and cable sections are often disposed of before forensic investigation can take place.

PD testing in a controlled HV laboratory environment is invaluable as the PD defect type and PD signals are both known quantities. Comparative PD testing between an IEC 60270 system and commercial HFCT to obtain information on differences in PD characteristics is of great value to allow understanding of the relationships between these measures.

Secondly, for pattern recognition by automated intelligent (AI) software algorithms, a large volume of training data with known signal types and defect types is demanded. The effective operation of AI systems requires both a large volume of experimental data and the ability to automatically pre-process raw data to reject interference signals ${ }^{[8-10]}$. IEC 60270 recommends a threshold of two times that of detected white noise to separate the interference signals from the PD data ${ }^{[1]}$ as the Signal to Noise Ratio (SNR) of an IEC 60270 system is high. For PD 
signal detection by HFCT, even in HV laboratory conditions, the SNR is low. PD signal interpretation from HFCT detection systems is, therefore, challenging if interference signals are not effectively rejected.

To address the first issue, a comparative experiment which combined the laboratory-based IEC 60270 system and a typical on-line PD monitoring setup for cable systems was established. Comparative analysis of PD signal characteristics of the two systems are carried out and, based on this, recommendations for on-line PD monitoring of cable systems are made.

To address the second issue, an automatic, Synchronous Detection and Multi-information Fusion (SDMF) signal identification method, capable of identifying and separating PD and repetitive pulsed interference, is presented. The method is shown to be effective for data pre-processing of raw experimental data detected by HFCT with low SNR, and which could be applied for PD lab testing of other power apparatus, e.g. HV transformer, motor, Gas Insulated Switchgear (GIS), etc. The output of SDMF based signal identification, which are PD data from HFCT, could be applied to both statistical PD signals interpretation and to PD criteria identification and pattern recognition for HFCT based on-line PD condition monitoring systems, this aspect will be presented in a future paper.

\section{EXPERIMENTAL SETUP AND ARTIFICIAL DEFECTS}

Laboratory testing of five types of artificial defects in $11 \mathrm{kV}$ EPR cable was carried out. The artificial defects will be discussed in Section 2.1.

The PD data was collected using both a capacitive coupling method, based on IEC 60270, and a commercially available HFCT connected to a $1 \mathrm{GHz}$ LeCroy digital oscilloscope.

A high voltage AC supply was connected to the cable under test, with associated artificial defects, to generate PD signals for pattern recognition. Additional information on the experimental set-up will be provided in Section 2.2.

\subsection{EPR CABLE AND ARTIFICIAL DEFECTS}

The construction and dimensions of the layers of the EPR cable are shown in Fig. 1.

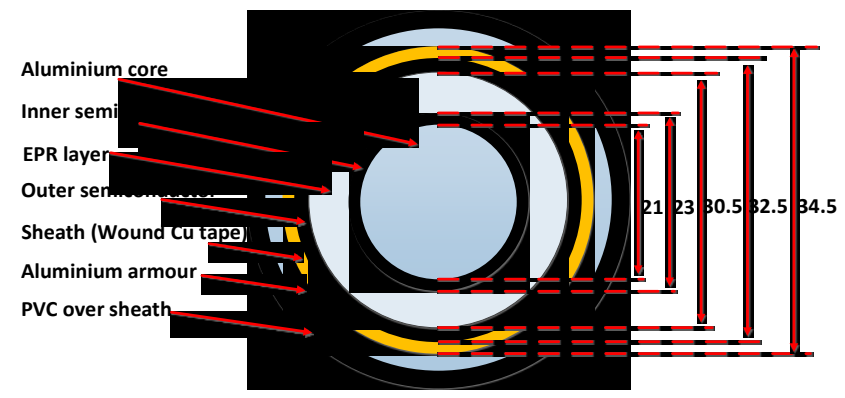

Fig. 1. The dimensions and layers of the EPR cable sample. Units: mm

As indicated in Fig. 1, the single-core $11 \mathrm{kV}$ cable has a stranded, compacted aluminum core, EPR insulation, removable semiconducting screen, copper tape screen, PVC bedding, aluminum wire armor and a PVC oversheath with reduced flame propagation characteristics ${ }^{[12]}$.

The five defect topologies investigated in this study, reported to exist in cables, are simulated as illustrated in Fig. 2 and Fig. 3.

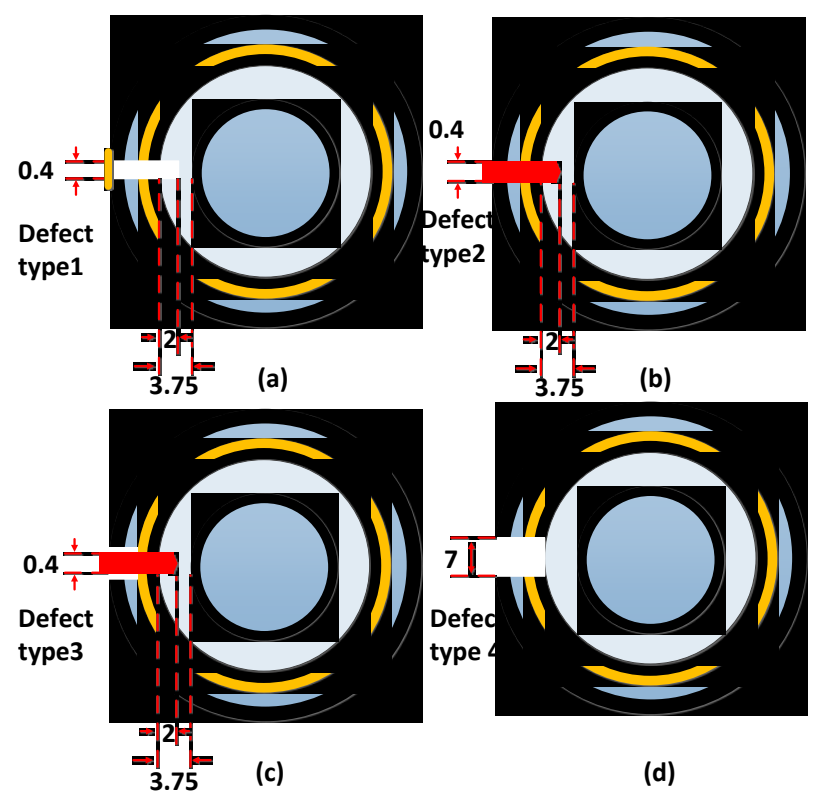

Fig. 2. Defect type and dimension: (a) 1: void in insulation; $0.4 \mathrm{~mm}$ diameter, $2 \mathrm{~mm}$ depth. (b) 2 : protrusion on outer conductor; $0.4 \mathrm{~mm}$ diameter, $2 \mathrm{~mm}$ depth. (c) 3 : floating protrusion; $0.4 \mathrm{~mm}$ diameter, $2 \mathrm{~mm}$ depth. (d) 4: breach in outer conductor; $7 \mathrm{~mm} * 7 \mathrm{~mm}$.

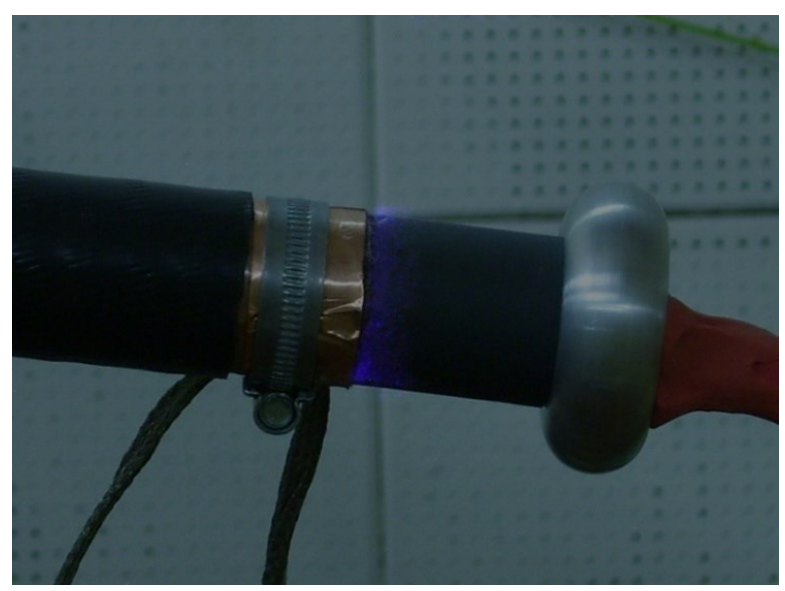

Fig. 3. Defect type 5: Surface discharge around end termination.

To generate defect type 1, void in cable insulation, a cylindrical void was generated by drilling a hole from the outer wall towards the inner conductor, using a precision $0.4 \mathrm{~mm}$ diameter printed-circuit-board drill. As shown in Fig. 3(a), copper tape is placed over the hole, in touch with the outer conductor, to seal the defect.

Defects type 2 and 3, replicate the situation where a metallic protrusion occurs due to a manufacturing defect or external damage ${ }^{[12]}$. The presence of these defects leads to a strongly inhomogeneous field which will provide a site where PD is likely to occur. Type 2 protrusions are created by inserting a printed-circuit-board drill into the cable: the drill is left in 
contact with the outer conductor, the aluminium armour and the PVC over sheath. Defect type 3 is a floating protrusion, i.e. there is no connection between the conductive parts and the drill.

Defect type 4 , simulates a breach in outer conductor, a delamination or interruption in the semiconducting or conductor layers, which may also occur due to manufacturing defects or during installation. This type of fault is created by cutting off a $7 \mathrm{~mm} * 7 \mathrm{~mm}$ area from the semiconductor, sheath, aluminum armor, PVC over sheath layers of the EPR cable, as shown in Figure 3(d).

PD may also occur due to incomplete or incorrect installation of stress cones at a cable's end terminations. Provided sufficient gap exists between inner and outer conductors at the end termination, the likelihood of breakdown is less than that of the internal fault types described above ${ }^{[12]}$. Defect type 5, shown in Fig. 3, is created by exposing part of the outer copper sheath and connecting it to earth.

\subsection{EXPERIMENTAL SETUP}

A commercially available HFCT and an IEC $60270^{\text {[11] }}$ testing system were combined in the laboratory for PD testing. The commercial HFCT adopted has been applied in PD online monitoring systems for many years, and used successfully by some authors in previous work ${ }^{[13]}$. The frequency response of the HFCT, as shown in Fig. 4, has a passband of $20 \mathrm{kHz}$ to $20 \mathrm{MHz}$. The connection of the systems to the LeCroy 104Xi digital oscilloscope is shown in Fig. 5.

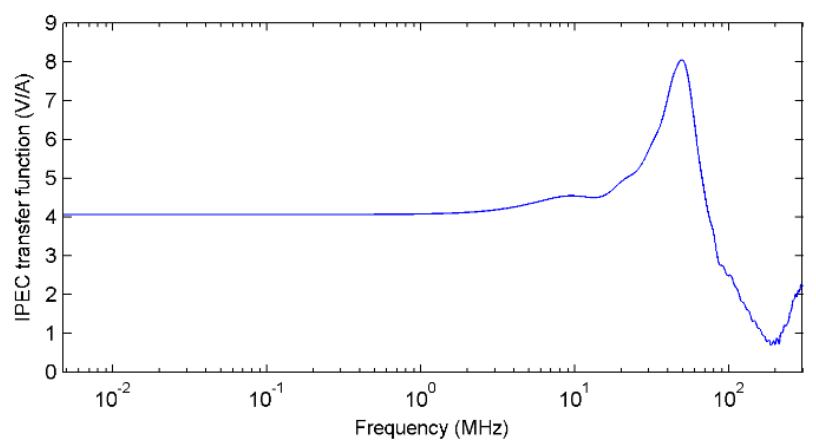

Fig. 4. HFCT frequency response

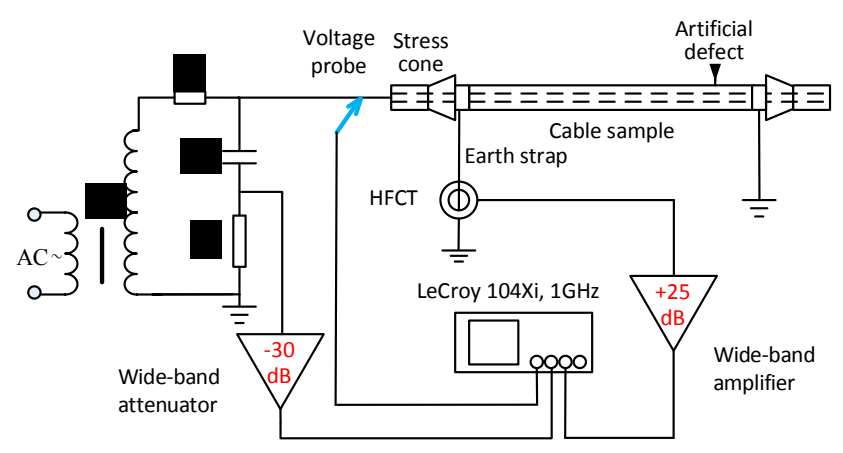

(b)

Fig. 5. PD detection system combining a commercial HFCT and an IEC60270 system. Data was measured relative to the $50 \mathrm{~Hz}$ AC supply. $\mathrm{C}_{\mathrm{k}}$ represents the IEC coupling capacitor and $\mathrm{Z}_{\mathrm{m}}$ the measurement impedance.

EPR cable samples of length $1.5 \mathrm{~m}$ to $2 \mathrm{~m}$, each containing one of the five artificial defects described in section 2.1, were connected (one at a time) to the high voltage supply for PD testing. As shown in Fig.6, a voltage probe was used to obtain the $50 \mathrm{~Hz}$ phase information and as the trigger for PD data acquisition. The signal from the HFCT is amplified by a wideband amplifier and, as the PD signals from the IEC 60270 measurement impedance $Z_{m}$ are of high amplitude, a wideband attenuator was applied to reduce the signal to the input limits of the oscilloscope $( \pm 10 \mathrm{~V})$. The signals from the HFCT and the IEC 60270 measurement impedance $Z_{\mathrm{m}}$ are synchronously logged for equitable comparisons. The oscilloscope captured raw PD data using a data acquisition rate of $100 \mathrm{MS} / \mathrm{s}$. The time base was set to $20 \mathrm{~ms}$, with the period of the $50 \mathrm{~Hz}$ power supply frequency.

One experimental setup is shown in Fig. 6.

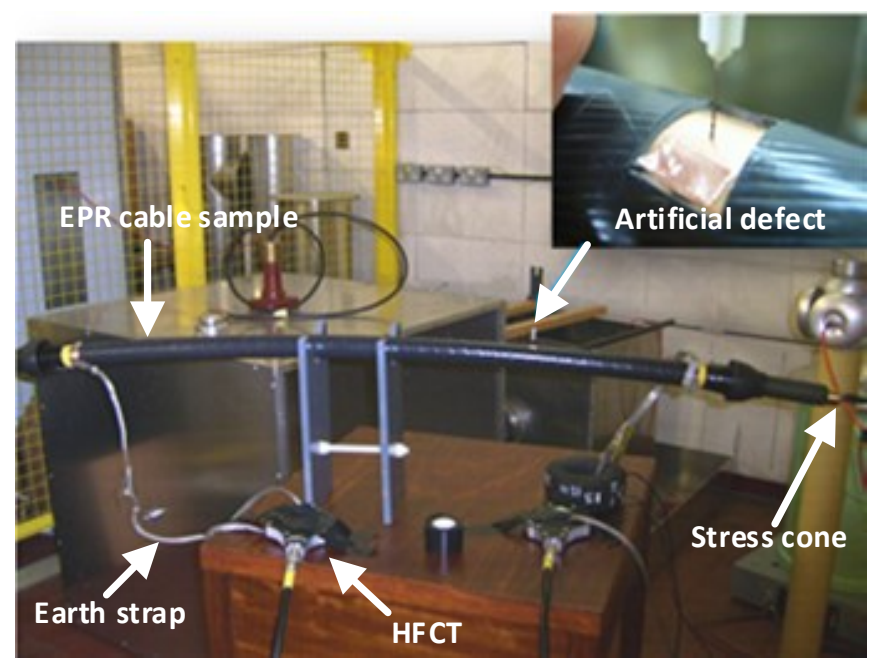

Fig. 6. Experimental setup for EPR cable sample, showing an example defect, earth strap and stress cone.

The voltage was increased in $1 \mathrm{kV}$ increments from 0 to $\mathrm{PD}$ Inception Voltage (PDIV), then taken beyond to a predetermined maximum level. For defect types 1, 4 and 5, the maximum value was the rated voltage of the cable, $11 \mathrm{kV}$. For defect types 2 and 3, the maximum voltage was $13 \mathrm{kV}$ and 12 $\mathrm{kV}$ respectively. Data was logged for each voltage level. The test voltages and the number of data sets for each test are shown in Table 1.

Due to the high PD count for defect type 5, fewer data sets were required to obtain useful information. To identify the defect type from the acquired data, it is expected that over 400 transient pulses will need to be extracted from the raw data.

Table 1. PD test voltage and number of sets of $20 \mathrm{~ms}$ data for each defect.

\begin{tabular}{c|c|c|c|c|c|c|c|c|c|c}
\hline $\begin{array}{c}\text { Defect } \\
\text { Type }\end{array}$ & $\begin{array}{c}5 \\
\mathrm{kV}\end{array}$ & $\begin{array}{c}6 \\
\mathrm{kV}\end{array}$ & $\begin{array}{c}7 \\
\mathrm{kV}\end{array}$ & $\begin{array}{c}8 \\
\mathrm{kV}\end{array}$ & $\begin{array}{c}9 \\
\mathrm{kV}\end{array}$ & $\begin{array}{c}10 \\
\mathrm{kV}\end{array}$ & $\begin{array}{c}11 \\
\mathrm{kV}\end{array}$ & $\begin{array}{c}12 \\
\mathrm{kV}\end{array}$ & $\begin{array}{c}13 \\
\mathrm{kV}\end{array}$ & SUM \\
\hline Type 1 & 50 & 50 & 50 & 50 & 50 & 50 & 50 & 0 & 0 & 350 \\
\hline Type 2 & 0 & 50 & 50 & 50 & 50 & 50 & 54 & 53 & 52 & 409 \\
\hline Type 3 & 0 & 51 & 50 & 50 & 26 & 50 & 52 & 61 & 0 & 340 \\
\hline Type 4 & 0 & 0 & 50 & 50 & 51 & 52 & 51 & 0 & 0 & 254 \\
\hline Type 5 & 0 & 0 & 10 & 10 & 10 & 10 & 10 & 0 & 0 & 50 \\
\hline
\end{tabular}




\section{SDMF BASED INTERFERENCE REJECTION FOR EXPERIMENTAL DATA}

\subsection{NOISE AND INTERFERENCE FROM DEFECTS}

Example sets of data from defect types 1 to 5 as detected by the HFCT and IEC 60270 systems are shown in Fig. 7. Fig. 7(a) to (e) shows signals from defect types 1 to 5 respectively. Data in green, with axis on the right hand side of the figure, are PD signal detected by the IEC 60270 system. Data in red, with axis on the left hand side of the figure, are from the HFCT.

Three typical noise and interference signals were detected during the experiments: white noise, regular interference signals and random interference signals.

White noise was detected during PD testing the five types of defect. The SNR of data gathered using the HFCT is lower than that in signals gathered using the IEC testing system. IEC 60270 recommends setting the threshold value for PD pulse detection at two times the level of white noise but, as shown in Fig. 7 (a), this is a challenge for PD detection using HFCT. When PD signals have a similar magnitude to the noisy raw data then significant loss of detected PD will occur unless appropriate interference rejection techniques are applied.

In addition to the white noise detected in all data sets, other pulsative noise signals were detected. During testing of defect types 2 and type 3 regular pulsative interference signals were detected, examples of strong regular pulses are indicated with arrows in Fig. 7 (b) and Fig. 7 (c). Additionally, random pulsative interference signals were detected during some tests. As some of the regular interference pulses have similar magnitude to PD, if the threshold for PD extraction is set at a level appropriate to the white noise then both PD and regular interference signals will be extracted from raw data.

For signal interpretation and pattern recognition of PD detected by HFCT, it is therefore essential to correctly extract PD signals from raw data with white noise, regular interference signal and random interference signal. In the following section the development of an automatic algorithm, capable of processing large volumes of data to separate PD from other signals and to organise the data for recognition systems is outlined.

\subsection{SDMF BASED INTERFERENCE SIGNAL REJECTION}

Examples of transient PD pulses contained within the signals captured and shown in Fig. 7 (b) are presented in Fig. 8.

Transient signals from HFCT and IEC 60270 systems are clearly different, as seen in Fig. 8. PD pulse shapes from the HFCT have different characteristics compared with those detected of IEC 60270 (IEC pulses), e.g. the oscillation tail of HFCT transients persist for longer than that of IEC pulses. IEC pulses always arrive at the oscilloscope about $100 \mathrm{~ns}$ after the HFCT pulses, due to the different responses and cable transfer times. If a fixed time window of $500 \mathrm{~ns}$ is placed around an HFCT pulse then the IEC pulse is contained in the time window. If a pulse has the correct shape and this time dependency, then the pulse is considered to be a PD pulse.
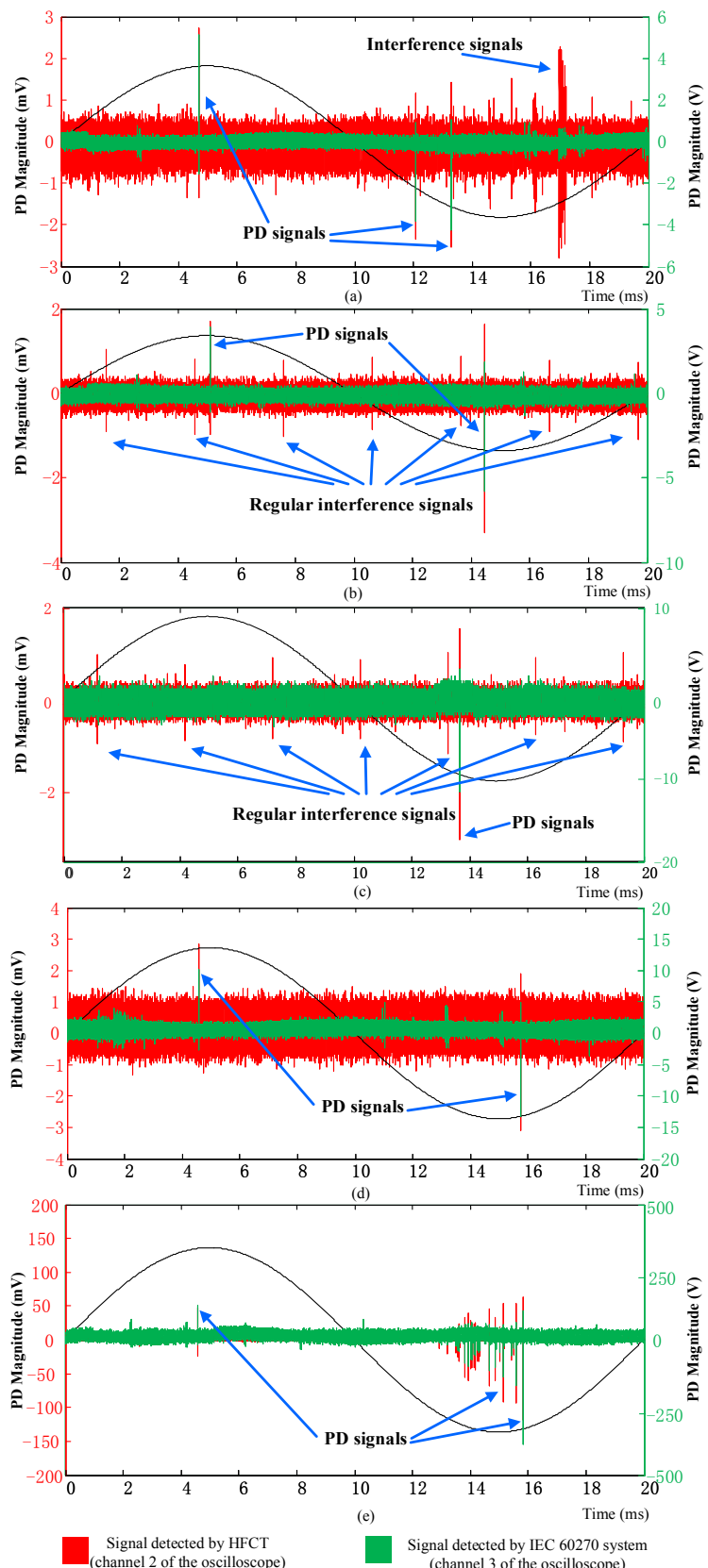

Fig. 7. Examples of (a) Type 1, (b) Type 2, (c) Type 3, (d) Type 4, (e) Type 5 PD data.

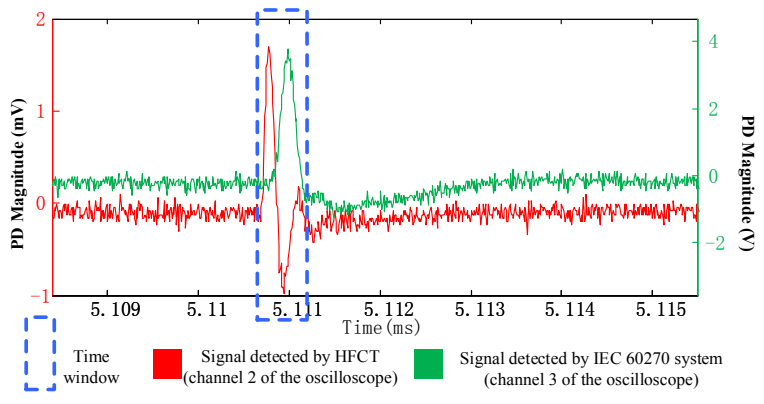

Fig. 8. PD Transient pulses from HFCT (lower trace) and IEC 60270 (upper trace). 
A novel Synchronous Detection and Multi-information Fusion (SDMF) based signal identification method has been developed for automatic PD and interference signal identification from the raw data captured in the experiments discussed above. A flowchart of SDMF based PD signal identification process is shown in Fig. 9.

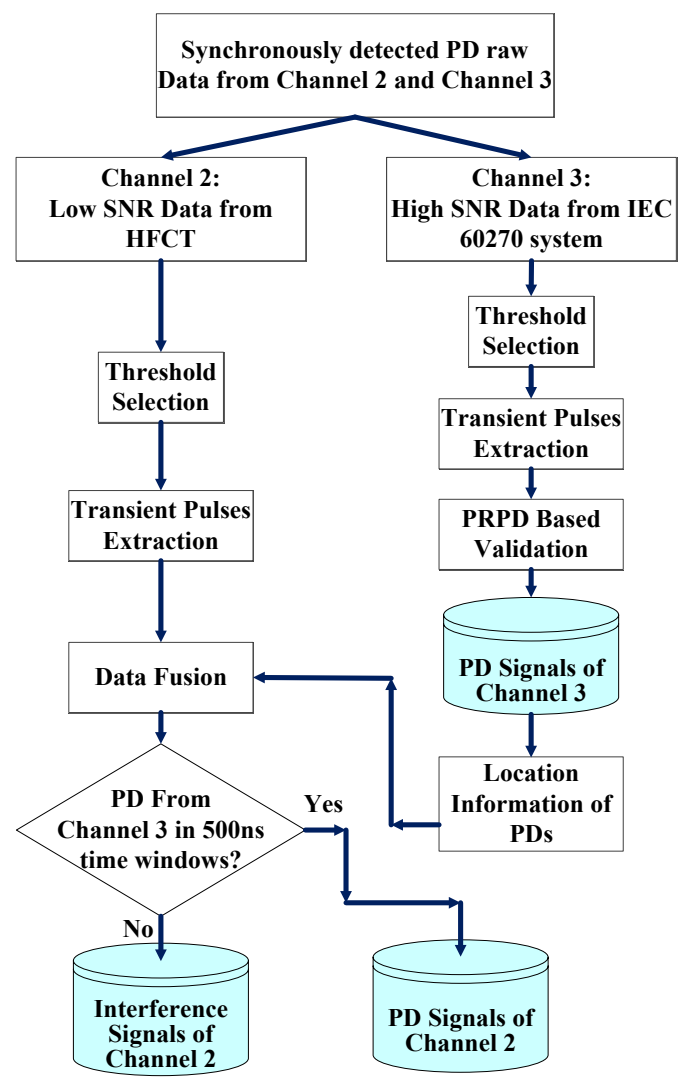

Fig. 9. Flow chart of SDMF based PD signal identification

In Fig. 9, data acquisition for channel 2 and channel 3 are fully synchronised with the AC signal collected in Channel 1. The raw data from an HFCT and from an IEC detection system (channels 2 and 3 respectively) are logged and processed in pairs.

Data from the IEC 60270 system has a high SNR and few interference signals. This data is processed first, according to threshold selection, transient pulse extraction and PRPD based PD signal validation. Using the PD signal location information, e.g. $16.556 \mathrm{~ms}$, the information is applied to PD signal identification for the HFCT data.

Data from the HFCT channel has a low SNR: data extracted, both PD and interference signals, are fused with the location information from the IEC channel. The data fusion judgement is carried out based on the $500 \mathrm{~ns}$ window discussed previously. If the signals do not show good correlation the pulses are judged to be interference signals.

SDMF based PD and interference signals detected by HFCT from defect type 1 are shown in Fig. 10.

Data in green are PD signals, data in black are interference signals identified by the method shown in Fig. 9. Fig. 10 (a) shows the PRPD pattern in terms of maximum magnitude of transient pulses; Fig. 10 (b) shows the PRPD pattern in terms of Equivalent Bandwidth ${ }^{[14]}$ of transient pulses; Fig. 10 (c) shows the PRPD pattern in terms of skewness of transient pulses. The visualisation of PRPD of different parameters proves the effectiveness of the SDMF based interference signals rejection.
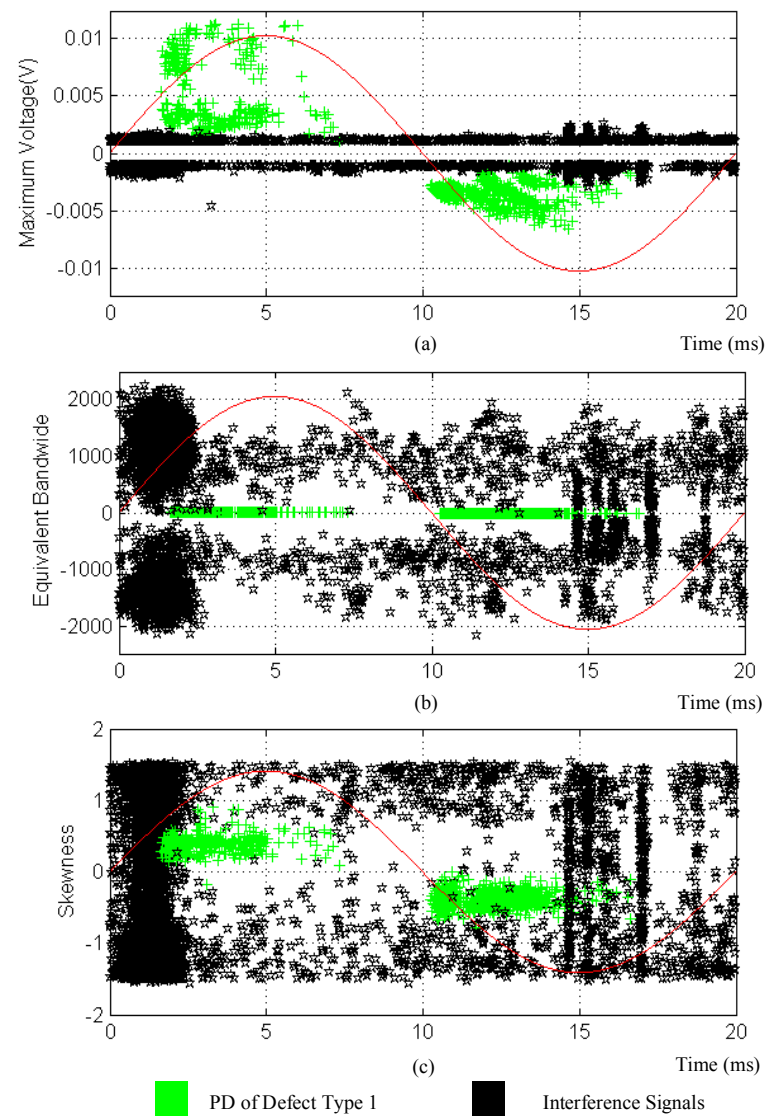

Fig. 10. Identified PD and interference signals of defect type one captured by HFCT, (a) PRPD of maximum voltage, (b) PRPD of equivalent bandwidth, (c) PRPD of skewness.

SDMF based PD identification of five defect types are carried out: results are shown in Fig.11. IEC system results are shown in Fig. 11 (a), HFCT are shown in Fig. 11 (b). 

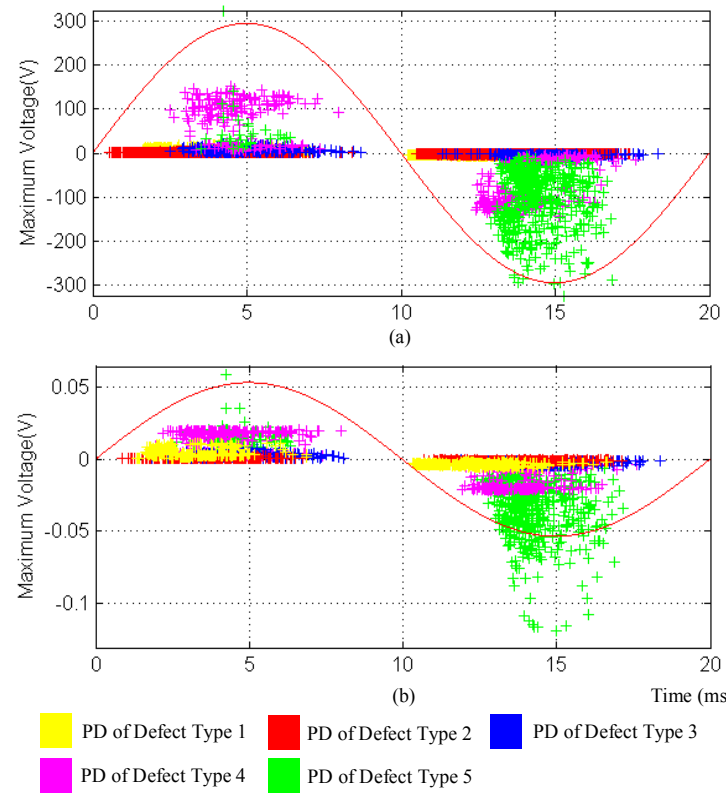

Fig. 11. PD signals from defect types 1 to 5 , (a) PD signals from the IEC 60270 system, (b) PD signals from the HFCT.

\section{Comparative AnAlysis Of PARTIAL DischaRge DATA DETECTED BY HFCT AND IEC 60270 SYSTEM}

Based on the PD data extracted by SDMF methods, statistical analysis is carried out to compare the PD activity behaviour of the five types of defects.

\subsection{VARIATION IN PD MAGNITUDE WITH APPLIED VOLTAGE}

Violin plots are a convenient way of graphically depicting groups of numerical data, they combine a boxplot and a (doubled) kernel density plot ${ }^{[15]}$. For each violin plot, five key data parameters are indicated, i.e. maximum, minimum and median values and first and third quartiles. Violin plots of maximum PD magnitude of transient pulses in terms of applied voltage are shown in Fig. 12. In Fig. 12 (a), value 1 is the maximum value; value 2 is the third quartile; value 3 is the median value; value 4 is the first quartile and value 5 is the minimum value. Violin plots also shows the statistical kernel density of the samples, in terms of a double distribution curves.

Fig. 12 (a) contains 7 violin plots, which represent the statistical results of PD magnitude of defect type 1 changing with the applied voltage, from $5 \mathrm{kV}$ to $11 \mathrm{kV}$.

Fig. 12 (a) to (e) show violin plots of PD magnitude for five artificial defect types using statistical analysis of the HFCT data. Fig. 12 (f) to (j) are the PD magnitude violin plots of the statistical analysis of the IEC data for the same faults.
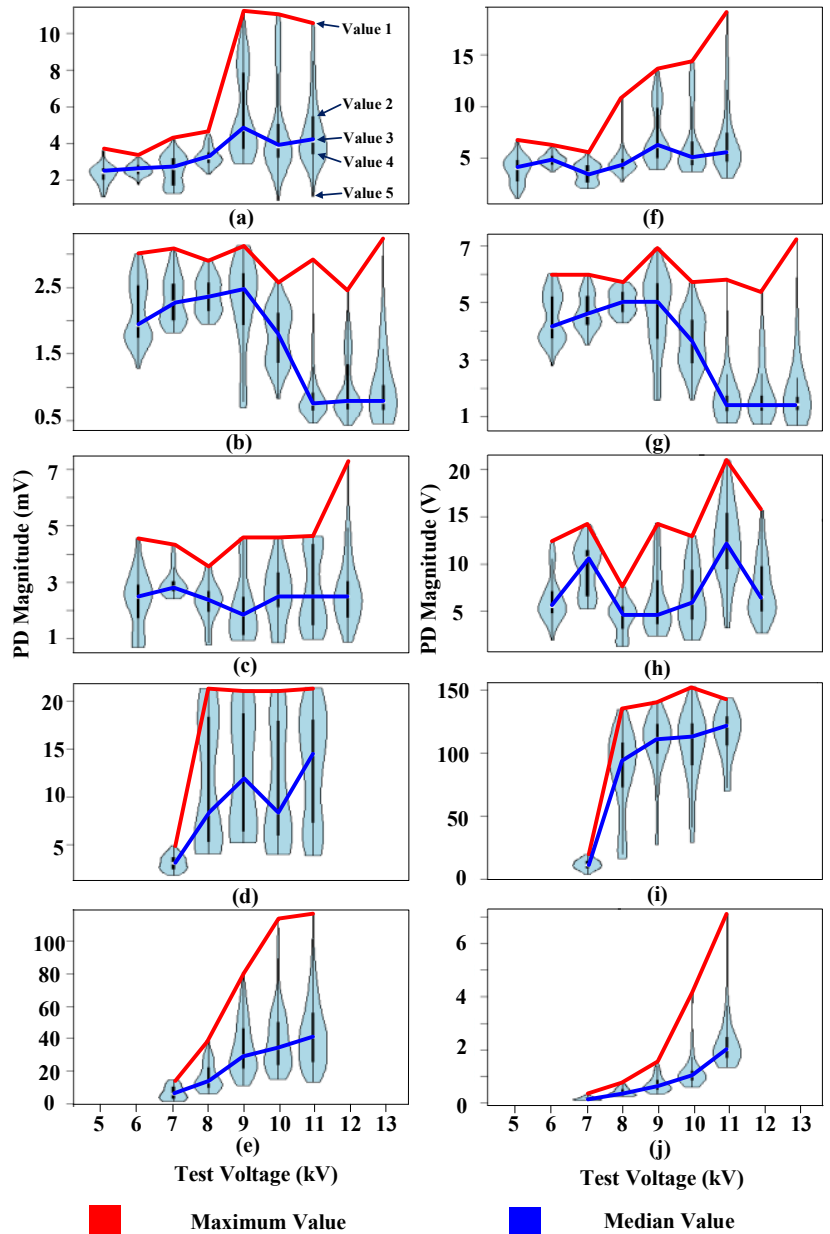

Fig. 12. Violin plot of PD magnitude from defects (a) Type 1 HFCT, (b) Type 2 HFCT, (c) Type 3 HFCT, (d) Type 4 HFCT, (e) Type 5 HFCT: (f) Type 1 IEC, (g) Type 2 IEC, (h) Type 3 IEC, (i) Type 4 IEC, (j) Type 5 IEC.

From Fig. 12 the following conclusions may be drawn:

Firstly, as the magnitudes of HFCT PD signals are in $\mathrm{mV}$ and those of IEC PD signals are in V, the PD signal level from the IEC 60270 system is always much greater than that from the HFCT sensor. It is, however, essential that research on signal processing and pattern recognition is based on commercial HFCTs if effective PD on-line monitoring system is to be carried out.

Secondly, as PD signals from the commercial HFCT are of small magnitude, e.g. the median value of PD signals for defect types 1, 2 and 3 is less than $5 \mathrm{mV}$ (Fig. 12(a) - (c)), it is a challenge to extract PD signals in data from noisy industrial environments, as the white noise of most industrial detection systems is more than $5 \mathrm{mV}$.

Thirdly, although the median PD magnitudes increase with increasing voltage for most faults, for type 2 the median PD magnitude decreases with voltages over $9 \mathrm{kV}$ (Fig. 12(b) and Fig. 12(g)). 


\subsection{VARIATION IN PD PULSE NUMBER WITH APPLIED VOLTAGE}

Violin plots of PD numbers in $20 \mathrm{~ms}$ with applied voltage are shown in Fig. 12. As the number of PD pulses detected by HFCT and IEC 60270 systems is the same only one set of figures is presented.

For defect types 1, 3 and 4 the number of PD pulses in each set of data is low: in some cases there is only one PD pulse in $20 \mathrm{~ms}$. For types 1 and 3 the variation in PD numbers with increasing voltage is inconsistent: for type 4 the number shows an increasing number of PD with increasing voltage. For these defects the trends for the PD number show strong similarity to the PD magnitude trends, Fig. 12.

For defect type 2, there is a rapid increase in PD number when the voltage is increased to $11 \mathrm{kV}$ and above. If compared with Fig. 12 (b), there is a rapid decrease in the median value of the PD magnitude at $11 \mathrm{kV}$ and above.

For defect type 5, there is a rapid increase in PD number as the voltage is increased throughout the test. This trend is similarly shown in PD magnitude, Fig. 12 (e) and (j).

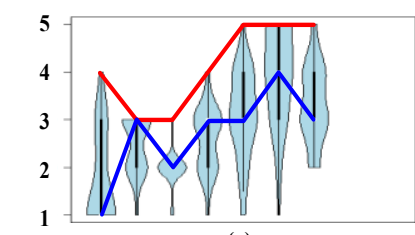

(a)
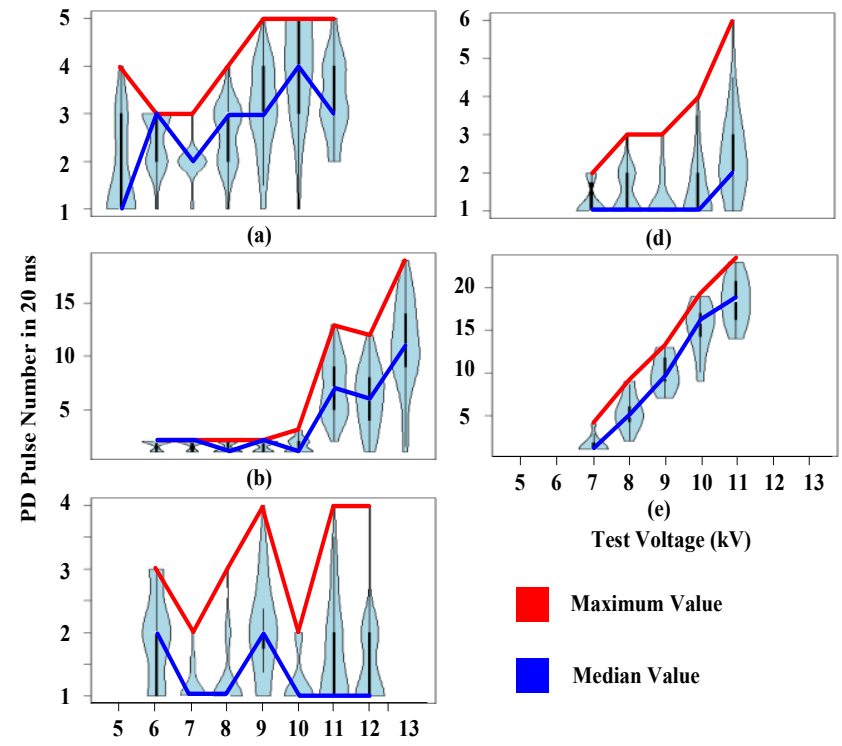

(d)

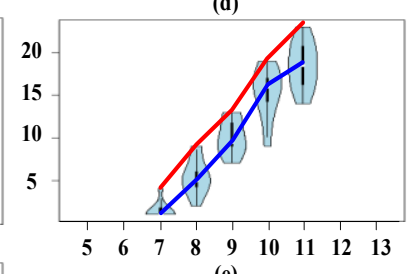

(e)

Test Voltage (kV)

Maximum Value

Median Value

(c)

Test Voltage $(\mathrm{kV})$

Fig. 13. Violin plot of PD Number in $20 \mathrm{~ms}$ for defects (a) Type 1, (b) Type 2, (c) Type 3, (d) Type 4, (e) Type 5.

\subsection{CASE STUDY: FLASHOVER DURING DEFECT TYPE 2 EXPERIMENT}

During a test on defect type 2 , after the voltage was increased to $13 \mathrm{kV}$, a flashover incident occurred. This caused damage to both the tip of the protrusion and the EPR insulation of the cable, as shown in Fig. 14. Analysis of data presented in sections 4.1 and 4.2 indicates increasing number of PD, Fig. 13 (b), and decrease of PD magnitude, Fig. 12 (b). It is possible that, before serious insulation degradation, the fault is in stage one, which shows a higher PD magnitude and a lower pulse number; after the serious insulation degradation, the fault is in stage two, with lower PD magnitude and higher pulse numbers.
A rapid decrease of PD magnitude (Fig. 12 (b)) and a rapid increase of pulse numbers (Fig. 13 (b)) might be an effective identifier of serous insulation degradation, which should be cautioned during on-line PD monitoring of EPR cables.

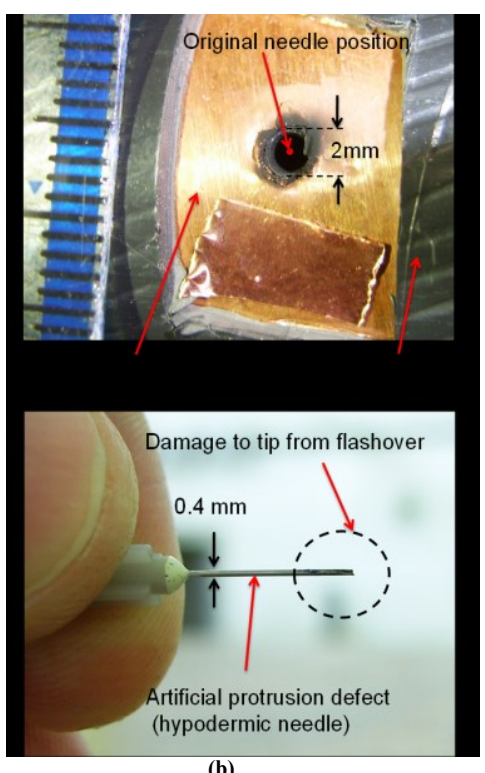

(b)

Fig. 14. Flashover of defect type 2 Damage to (a) EPR cable, (b) needle.

\subsection{VARIATION IN PD CHARACTERISTICS WITH SIZE OF VOID DEFECT}

To investigate the variation of PD characteristics when the size of a void in a cable increases, e.g. with insulation degradation, the diameter of a void, shown as a defect type 1 in Fig. 2, is changed from $1 \mathrm{~mm}$ to $3 \mathrm{~mm}$ in steps of $0.5 \mathrm{~mm}$. The depth of the voids is maintained at $2 \mathrm{~mm}$, as defined in the characteristics of the defects shown in Table 2. The test voltage for each defect type was varied, in $1 \mathrm{kV}$ steps, up to the rated voltage of the cable, $11 \mathrm{kV}$. The values of voltages for which results are reported are listed in Table 2.

Table 2. Characteristics of defect types 6 to 10 and test voltages

\begin{tabular}{c|c|c|c}
\hline Defect Type & $\begin{array}{c}\text { Diameter of } \\
\text { void }(\mathrm{mm})\end{array}$ & $\begin{array}{c}\text { Depth of } \\
\text { void }(\mathrm{mm})\end{array}$ & Testing voltage \\
\hline Type 6 & 1 & 2 & $8 \mathrm{kV}, 9 \mathrm{kV}, 10 \mathrm{kV}, 11 \mathrm{kV}$ \\
\hline Type 7 & 1.5 & 2 & $10 \mathrm{kV}, 11 \mathrm{kV}$ \\
\hline Type 8 & 2 & 2 & $8 \mathrm{kV}, 9 \mathrm{kV}, 10 \mathrm{kV}, 11 \mathrm{kV}$ \\
\hline Type 9 & 2.5 & 2 & $8 \mathrm{kV}, 9 \mathrm{kV}, 10 \mathrm{kV}, 11 \mathrm{kV}$ \\
\hline Type 10 & 3 & 2 & $9 \mathrm{kV}, 10 \mathrm{kV}, 11 \mathrm{kV}$ \\
\hline
\end{tabular}

Violin plots of maximum PD magnitude for different diameters of void are shown in Fig. 15.

From Fig. 15, the following observations can be made: Generally speaking, although the relationship is not linear, PD magnitude increases with size of void.

Data analysis, not presented, has shown that there is no change in the number of PD pulses as the size of the void changes. For defect types 6 to 10 the number of PD pulses stays at 1 to 5 per $20 \mathrm{~ms}$. 


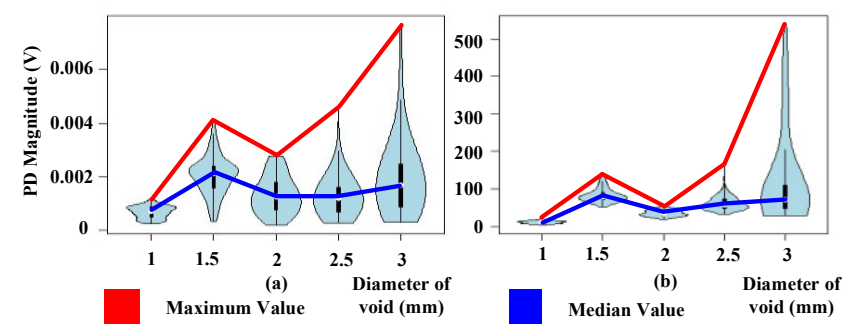

Fig. 15. Violin plot of PD magnitude for a range of void diameters: (a) HFCT, (b) IEC 60270.

From the analysis in sections 4.1, 4.2 and 4.4 of the paper conclusions may be drawn, i.e. for PD based condition monitoring of a cable system, the symptoms of serious insulation degradation might be:

Rapid increase of PD magnitude (Fig. 15) due to changing dimension of the void;

Rapid decrease of PD magnitude (Fig. 12 (b)) due to changing local stress with defect type;

Rapid increase in PD number (Fig. 13 (b)) due to variation in local stress.

\section{Discussion AND Conclusions}

This paper has presented information gathered from experimental work on 5 defects introduced to $11 \mathrm{kV}$ singlephase EPR cable. The defects replicate faults which are found in in-service cables. The range of electrical stress parameters applied to the cable faults is provided. A method of comparing IEC and HFCT data (Synchronous Detection and Multi-information Fusion) allows signal interpretation and pre-processing of PD data from the defects. Based on the comparative analysis of data collected from an IEC 62070 system and a commercially available HFCT, characteristics of PD signals are reported.

Conclusions are summarized as follows:

- The proposed SDMF based PD signal identification is effective for automatous PD and interference signal identification and to processing of large volumes of experimental PD data if two kinds of defection system are fully synchronised.

- PD from EPR cable detected by a commercial HFCT sensor was of relatively low magnitude, i.e. median value of PD magnitude from defect types 1 to 3 was below $5 \mathrm{mV}$ (Fig. 12 (a) - (c)).

- The magnitude of PD signals from an IEC 60270 system was observed to be several hundred times greater than those from a commercial HFCT sensor (Fig. 12). As IEC systems are challenging to install in practical situations, alternative methods of signal processing must be developed and deployed in order to make full use of HFCT technology.

- Statistical analysis shows that for insulation related $\mathrm{PD}$, pulse number in a $20 \mathrm{~ms}$ period is low. Despite insulation breakdown, PD pulse number in defect types 1 to 4 are fewer than 6 in $20 \mathrm{~ms}$; the median values of PD pulse number for defect types 1 to 4 are 1,2 and 3. Sometimes there is only one negative pulse in 20 ms (Fig. 13 (a) (c) (d)).

- From analysis of PD characteristics prior to the flashover incident, indicator of serious insulation degradation of EPR cables might be the rapid decrease of PD magnitude (Fig. 12 (b)) and the rapid increase of PD pulse numbers (Fig. 13 (b)).

- Analysis of PD characteristics when the size of a void is increased, to simulate insulation degradation, shows that PD magnitude increases with size of void but the relationship between PD magnitude and size of void is not linear, and there is no change in the number of PD pulses when the size of void is increased.

Based on the work carried out in this paper, 5672 sets of PD signals and 9687 sets of interference signals detected by HFCT have been automatously extracted from raw data. 2000 sets of PD signals with known defect type and 2000 interference signal have been randomly selected for further pattern recognition investigation. The results of the study will be published in a future paper.

\section{ACKNOWLEDGEMENT}

The authors would like to thank National Natural Science Foundation of China for funding the research under grants 51541705. The authors also would like to thank EPSRC (UK) for funding the research, under grants EP/G028397/1 and $\mathrm{EP} / \mathrm{G} 029210 / 1$.

\section{REFERENCES}

[1] A. J. Hunter, P. L. Lewin, L. Hao, C. Walton, M. Michel, "Autonomous classification of PD sources within three-phase $11 \mathrm{kV}$ PILC cables", IEEE Transactions on Dielectrics and Electrical Insulation, Vol. 20, No. 6, pp. 2117-2124, 2013.

[2] X. Peng, C. Zhou, D. M. Hepburn, M. D. Judd, W. H. Siew, "Application of K-Means Method to Pattern Recognition in On-line Cable Partial Discharge Monitoring", IEEE Transactions on Dielectrics and Electrical Insulation, Vol. 20, No. 3,pp. 754-761, 2013.

[3] L. Hao, P. L. Lewin, "Partial Discharge Source Discrimination using a Support Vector Machine", IEEE Transactions on Dielectrics and Electrical Insulation, Vol. 17, No.1, pp. 189 -197. 2010.

[4] A. Rizzi, F. M. F. Mascioli, F. Baldini, C. Mazzetti, R. Bartnikas, "Genetic Optimization of a PD Diagnostic System for Cable Accessories", IEEE Transactions on Power Delivery, Vol. 24, No.3, pp. $1728-1738,2009$.

[5] H. Ma, J. C. Chan, T. K. Saha, C. Ekanayake, "Pattern Recognition Techniques and Their Applications for Automatic Classification of Artificial Partial Discharge Sources", IEEE Transactions on Dielectrics and Electrical Insulation, Vol. 20, No. 2, pp. 468-478, 2013.

[6] A. J. Mcgrail, E. Gulski, E. R. S. Groot, D. Allan, D. Birtwhistle, T. R. Blackburn, "Data Mining Techniques to Assess the Condition of High Voltage Electrical Plant", CIGRE Working Group 15.11, 2002.

[7] C. Zhou, M. Michel, D. M. Hepburn, G. Zhang, "Rough Set Theory for Data Mining in an On-line Cable Condition Monitoring System", CIRED 2007, Vienna, Austria.

[8] J. Tang, F. Liu, X. Zhang, X. Liang, Q. Fan, "Partial discharge recognition based on SF6 decomposition products and support vector machine", IET Science Measurement \& Technology, Vol.6, No.4, pp. 198-2041, 2012. 
[9] L. Li, J. Tang, Y. Liu, "Partial Discharge Recognition in Gas Insulated Switchgear Based on Multi-information Fusion", IEEE Transactions on Dielectrics and Electrical Insulation, Vol. 22, No. 2, pp. 1080-1087, 2015.

[10] S. M. Gargari, P.A.A.F Wouters, P. van der Wielen, E. F. Steennis, "Partial discharge parameters to evaluate the insulation condition of on-line located defects in medium voltage cable networks", IEEE Transactions on Dielectrics and Electrical Insulation, Vol. 18, No. 3, pp. 868-877, 2011.

[11] IEC International Standard 60270, "High Voltage Test Techniques Partial Discharge Measurements", International Electrotechnical Commission (IEC), Geneva, Switzerland, 3rd edition, 2000.

[12] A. J. Reid, X. Peng, X. Hu, M. D. Judd, W. H. Siew, C. Zhou, D. M. Hepburn, "Comparison Of Partial Discharge Characteristics From Insulation Defects In $11 \mathrm{kV}$ EPR Cable", Proc. 17th International Symposium on High Voltage Engineering, Hannover, Germany, 2011.

[13] C. Zhou, M. Michel, D.M. Hepburn, X. Song, "On-line partial discharge monitoring in medium voltage underground cables", IET Science Measurement and Technology, Vol.3, Iss.5, pp. 354-363, 2009

[14] G. C. Montanari, A. Cavallini, "A New Approach to Partial Discharge Testing of HV Cable Systems", IEEE Electrical Insulation Magazine, Vol. 22, No. 1, pp. 14-23, 2006.

[15] M. Correll, M. Gleicher, "Error Bars Considered Harmful Exploring Alternate Encodings for Mean and Error", IEEE Transactions on Visualization and Computer Graphics, Vol. 20, No. 12, pp. 2142$2151,2014$.

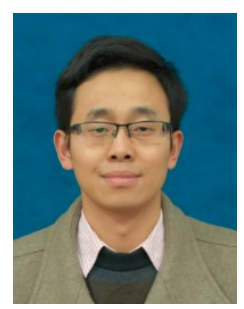

Xiaosheng Peng (M'11) received the B.Sc. and M.Sc. degrees from Huazhong University of Science and Technology, China in 2006 and 2009, respectively, and the Ph.D. in electrical engineering at Glasgow Caledonian University in 2012 funded by EPSRC. He has worked as a Post-Doctoral Researcher in Glasgow Caledonian University funded by EDF Energy. He is currently a lecturer in School of Electrical and Electronic Engineering of Huazhong University of Science and Technology. His research interests are partial discharge signal processing and condition monitoring of power plant. He is a member of IET.

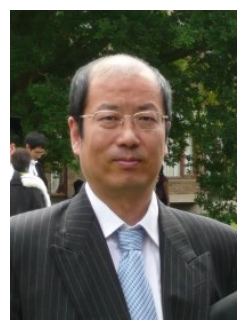

Chengke Zhou (M'06) received the B.Sc. and M.Sc. degrees in electrical engineering from Huazhong University of Science and Technology, China in 1983 and 1986, respectively, and the Ph.D degree from the University of Manchester U.K., in 1994. Since then, he worked in Glasgow Caledonian University, U.K., as a Lecturer, Senior Lecturer and in Heriot-Watt University as a Reader until 2007 when he went back to Glasgow Caledonian University as a Professor. He has published more than 100 papers in the area of partial discharge based condition monitoring of MV/HV plant and power system analysis. He is member of IET.

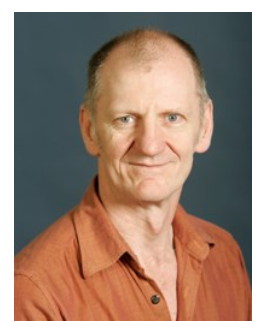

Donald M. Hepburn received his B.A. (Hons) from the Open University in 1987 and the Ph.D. degree from Glasgow Caledonian University (GCU) in 1994. He has many years of industrial research experience and has been involved in research into high voltage insulation systems at GCU for over 20 years. His research interests cover monitoring of chemical changes to insulation materials, application of electrical, acoustic and RF monitoring equipment to $\mathrm{HV}$ components and application of advanced digital signal processing to information from the monitoring techniques. He is a Senior Lecturer at $\mathrm{GCU}$ and is involved in industrial and academic research projects.
Alistair J. Reid (M'11-SM'15) graduated from the University of Strathclyde, UK, in 2004 with a B.Eng. (Hons) degree in Electrical and Mechanical Engineering and received the Ph.D. degree in 2007 for research on partial discharge monitoring. Subsequently, he has worked as a Post-Docroral Research at the University of Strathclyde, a Research Fellow at Glasgow Caledonian University and a Visiting Research Associate at California Institute of Technology. He is presently a Lecturer in the School of Engineering and Built Environment at Glasgow Caledonian University. His research interests include diagnostic monitoring techniques and systems, partial discharge, sensor design, embedded systems and energy harvesting. Alistair is a Senior Member of the IEEE and a committee member of the Universities High Voltage Network (UHVnet) in the UK.

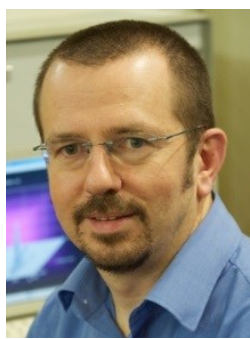

Martin D. Judd (M'02-SM'04) is the Technical Director of High Frequency Diagnostics Ltd. He graduated from the University of Hull in 1985 with a first class (Hons) degree in Electronic Engineering, after which he gained 8 years of industrial experience, first with Marconi Electronic Devices and then with EEV Ltd. Martin received his $\mathrm{PhD}$ from the University of Strathclyde in 1996 for research into the excitation of UHF signals by partial discharges in gas insulated switchgear. He has worked extensively on UHF partial discharge location techniques for power transformers and was latterly Professor of High Voltage Technologies at the University of Strathclyde, where he managed the High Voltage Research Laboratory. In 2014 he founded High Frequency Diagnostics, a contracting and consultancy business that works in partnership with companies and universities to maximize the impact of $R \& D$ outputs by utilizing them in new technologies and applications.

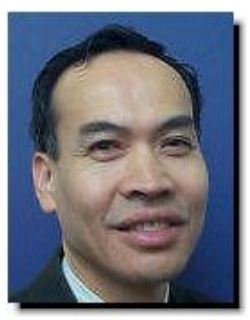

W. H. Siew (M'95) is a Reader in the Department of Electronic \& Electrical Engineering, University of Strathclyde, Glasgow, Scotland. He is a triple alumnus of the University of Strathclyde with degrees of B.Sc. (Hons) in electronic \& electrical engineering; Ph.D. in electronic \& electrical engineering; and Master of Business Administration. His areas of research interest include large systems electromagnetic compatibility; cable diagnostics; lightning protection; and wireless sensing systems. He is Convener of the CIGRE WG C4.208 and a member of the Technical Advisory Panel for the IET Professional Network on Electromagnetics. He is also a member of IEEE TC7. He is a Chartered Engineer and an MIEE. 